\title{
Chapter 29 \\ How Often Do You Open Your House \\ Windows When Heating is ON? \\ An Investigation of the Impact \\ of Occupants' Behaviour on Energy \\ Efficiency of Residential Buildings
}

\author{
Sherna Salim and Amin Al-Habaibeh
}

\begin{abstract}
Currently, there are many initiatives to thermally insulate buildings on the assumption that the more insulated the building is, the more efficient in terms of energy conservation it will perform. Many assessment systems assume a linear relationship between building insulation and energy conservation. The drawback of such hypotheses is that they ignore the effect of occupants' behaviour in their conclusions. In this study, the authors will examine the effect of people's behaviour, particularly windows' opening, as a behavioural pattern of occupants. It aims to study the impact of occupant's behaviour on energy consumption of residential buildings and to identify the key factors that influence occupants' behaviour; thus, providing ideas for improving energy efficiency by suggesting enhanced policies, approaches and techniques. The findings suggest that occupants' behaviour could have a greater influence on the energy efficiency of buildings in some cases when compared with their thermal insulation due to opening of windows in cold weather which causes air infiltration.
\end{abstract}

Keywords Energy efficient buildings • Energy consumption in buildings • Occupant behaviour $\cdot$ Air quality $\cdot$ Sustainability

\subsection{Introduction}

The UK government has committed to reduce its carbon footprint to nearly zero by the year 2050 [1]. To achieve this, a massive investment will be needed in clean energy generation and reductions in fossil fuel consumption. In this context several initiatives have been planned or taken place, such as the Green Deal, for insulating

S. Salim $(\bowtie) \cdot$ A. Al-Habaibeh

Product Innovation Centre, Product Design, Nottingham Trent University, Nottingham, UK

e-mail: sherna.salim2017@my.ntu.ac.uk

A. Al-Habaibeh

e-mail: Amin.Al-Habaibeh@ntu.ac.uk

I. Mporas et al. (eds.), Energy and Sustainable Futures, Springer Proceedings in Energy, https://doi.org/10.1007/978-3-030-63916-7_29 
1 to 3.7 million houses with solid wall insulation, by 2030 . There has been a steady increase in the number of households in the UK, since 1991, contributed by factors such as the increase in birth rate, net immigration and the long-term trend of single adult households [2]. According to International Energy Agency, energy use in buildings is influenced by six parameters: climate, building envelope, building energy and services system, indoor design criteria, building operation and maintenance and occupants' behaviour [3, 4]. Providing smart meters to every home and business by 2020 is another government commitment. Several policies have been brought forward by the government in the past decade to improve energy efficiency in the domestic sector. The green deal, The Energy Act 2011, incentives to improve insulation in houses (solid wall insulation and loft insulation) all concentrate on improving building performance by improving the fabrics of existing buildings. However, government statistics show that despite improvement to the buildings' fabric, houses do not meet the original energy set targets. This has been inferred as a result of a report after the analysis of data from a subset of 76 homes by the Innovate UK's Building Performance Evaluation Programme (BPE) [5]. In its strategies to achieve carbon budgets, it has been clearly stated that 'We can achieve a reduction in energy demand either by improving the energy efficiency of buildings, lighting and appliances, or by changing the way we behave so that we use energy more intelligently and reduce the amount we need.' [6].

Past decade has seen an increase in the evaluation of energy use in buildings. This has brought to notice that there is a considerable gap between the predicted and actual energy consumption in the investigated buildings. The authors of this paper have conducted a study analysing the thermal images of residential buildings on two winter night, when temperature was between $3-5{ }^{\circ} \mathrm{C}$. It was found that no matter how insulated the building is, occupants' behaviour of opening windows results in considerable loss of heat [7]. There has been an increasing evaluation of energy use in buildings in the past 15 years, and it has been widely acclaimed that there is a considerable gap between the predicted and actual energy consumption in buildings. Occupant behaviour is one of the most overlooked parameter during energy efficiency design of buildings $[8,9]$.

In a project [10] aimed at reducing domestic energy usage by $20 \%$, by exploring the relationship between the fabric of houses, heating systems and occupants' behaviour that work towards optimum comfort levels and the energy usage in the process, it has been found it is a complex problem and that there are significant variabilities between and within households over short and lengthy periods. They have found that thermostat settings vary from as low as $15{ }^{\circ} \mathrm{C}$ to as high as $30{ }^{\circ} \mathrm{C}$. Although energy costs have been cited as a source of concern, the setting is found to be based on comfort rather than cost for most participants. They also have found that central heating is used in many different ways; some of them adjusted the thermostat directly, some set timers and some turned the whole heating system on and off as required [10]. Bălan et al. used a rule-based control, in the simulations of the thermal model of a house, where the influence of occupancy is determined as a secondary heat input, therefore impacting the internal load [3]. 
Opening and closing of windows as an indication status of occupants' behaviour in a building could be very critical in energy consumption patterns as the authors have found that two houses with the same degree and type of insulation perform significantly different due to the difference in the occupants' behaviour of window opening and window closing [7]. This implies that window opening behaviour has significant influence on the energy consumption and it could be as important as thermal insulation. In this paper, a survey is presented to explore the response to window's opening in order to understand further the behaviour of people to support a better building design.

\subsection{Methodology}

To explore the impact of occupants' behaviour on energy efficiency of a building, with the focus on opening of windows, an on-line survey was conducted. It examined the windows-opening behaviour of people and its consequent effect on the energy efficiency of buildings. The survey aimed at people residing in the UK. A survey link, containing a brief information on the aim of the project and the questions, were sent through emails and social media groups to a collective of people across the UK. An ethical approval process was followed during this research work. For the quantitative measures, the survey was designed with a confidence level of $95 \%$ following a sample size of 195 respondents, with an error margin of $7 \%$.

\subsection{Survey Details}

Region: The response included residents from all parts of the UK, of which $56.7 \%$ were from the east midlands and the rest were scattered across the UK $(9.8 \%$ from greater London, 98\% from South East England, 8.2\% from West Midlands, etc.)

Type of house: The response included all types of houses; $33.8 \%$ live in semidetached houses, $25.6 \%$ in detached houses, $24.1 \%$ in flats and $12.8 \%$ of the respondents lived in terraced houses. While $52.8 \%$ of the people live in their own houses, $90 \%$ of the people who did the survey pay their own electricity and gas bills.

Ethnicity: $51.8 \%$ of the respondents were from Asian British background, while $36.5 \%$ were from white British/other white background; and the rest were from other ethnicities (Black, Arab, other multiple ethnic groups.)

Age range: The survey was answered by people from all age groups, as shown in Table 29.1.

Statistical analysis is carried out to analyse the patterns and the frequency of people opening their home windows. It is clear that if occupants frequently open or 
Table 29.1 Percentage of respondents for different age groups

\begin{tabular}{l|l}
\hline Percentage of respondents $(\%)$ & Age group \\
\hline 9.7 & $18-25$ \\
\hline 31.8 & $26-34$ \\
\hline 30.3 & $35-44$ \\
\hline 17.4 & $45-54$ \\
\hline 8.7 & $55-64$ \\
\hline 2.1 & $65-74$ \\
\hline
\end{tabular}

keep windows open when the heating system is on, this will have a negative effect on the energy conservation due to air infiltration.

\subsection{Results and Discussion}

The survey was distributed from November 2019 to February 2020. A total of 195 responses were received. Figure 29.1 shows the frequency of opening windows, by the respondents. It can be seen that although the frequency of window opening varied, $90.1 \%$ of the respondents open their house windows and only $9.9 \%$ never opened their house windows. Of the people who opened windows, $45.6 \%$ open windows at least once a day. About $44 \%$ of the people open windows for at least $30 \mathrm{~min}$ a day, of which $16 \%$ leave it open for $2-5 \mathrm{~h}$. About $77.8 \%$ of people open windows when the heating is ON, of which $17 \%$ open it very frequently (see Fig. 29.2).

The most common reason to open windows in any room in a house is to get some fresh air. Apart from that, people open kitchen windows to get rid of cooking odour; and they open bathroom windows due to condensation.

A relevant point to note is that although $86.5 \%$ of the people who have done the survey are graduates or post-graduates, $45.5 \%$ of the people do not know the type of insulation in their homes, which is evident from Fig. 29.3. This shows that the behaviour of the people is independent of their knowledge in relation to their building's insulation.
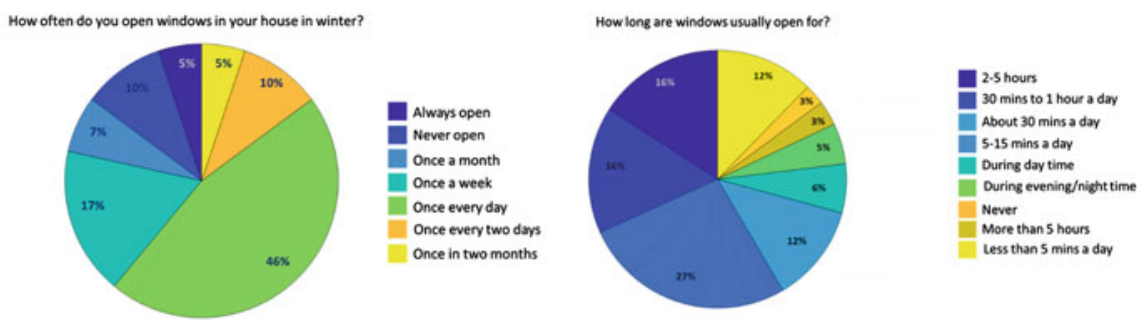

Fig. 29.1 Frequency of opening windows 
How often do you open windows when the heating is ON?

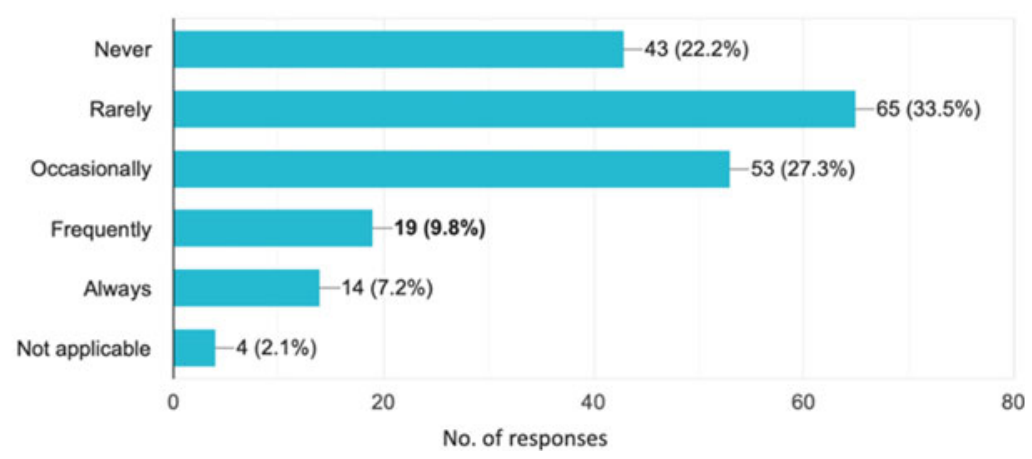

Fig. 29.2 Frequency of opening windows when heating is ON

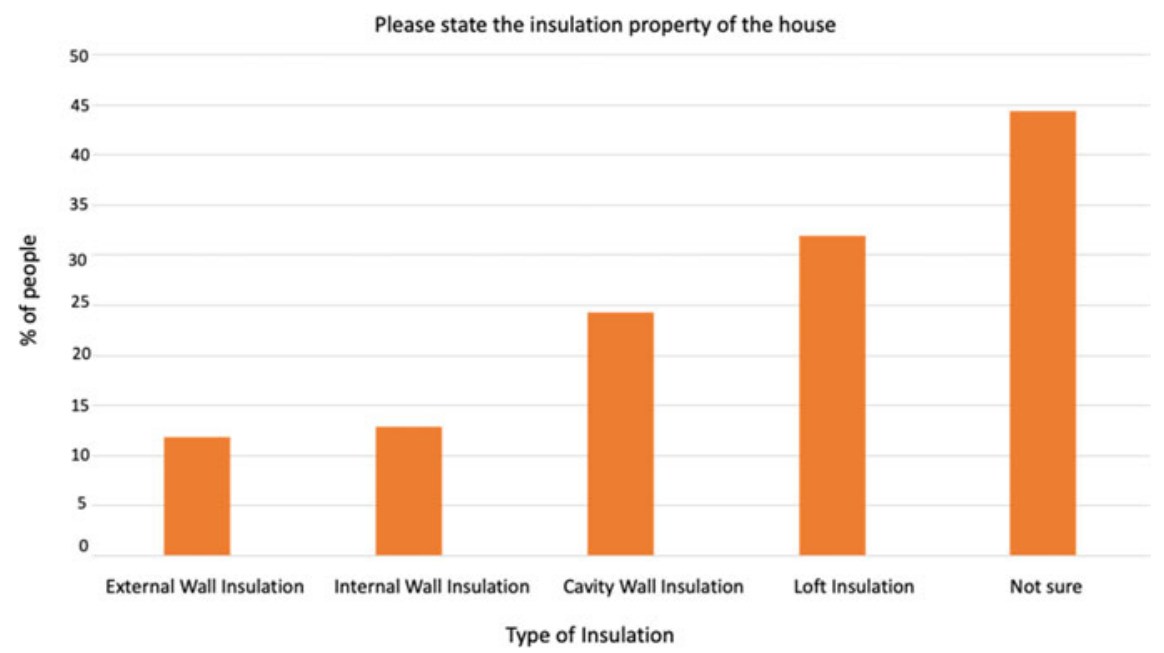

Fig. 29.3 Type of insulation as known to occupants

From the survey, it is evident that opening of windows is mainly a personal behaviour. For instance, let us analyse the response of participant 119 . He/she prefers have the ambient temperature of the house to be between $18-22{ }^{\circ} \mathrm{C}$. It is a detached house, with external wall insulation, internal wall insulation, cavity wall and loft insulation. In spite of this, the occupant opens the windows every day and for about $30 \mathrm{~min}$. On the other hand, participant 77 who prefers the same ambient temperature of $18-22{ }^{\circ} \mathrm{C}$, lives in a new built with cavity wall insulation and loft insulation; but leaves the windows closed at all time.

It can be seen that $77.8 \%$ of people open windows when heating is $\mathrm{ON}, 17 \%$ of which open windows very frequently. The most common reason for opening 


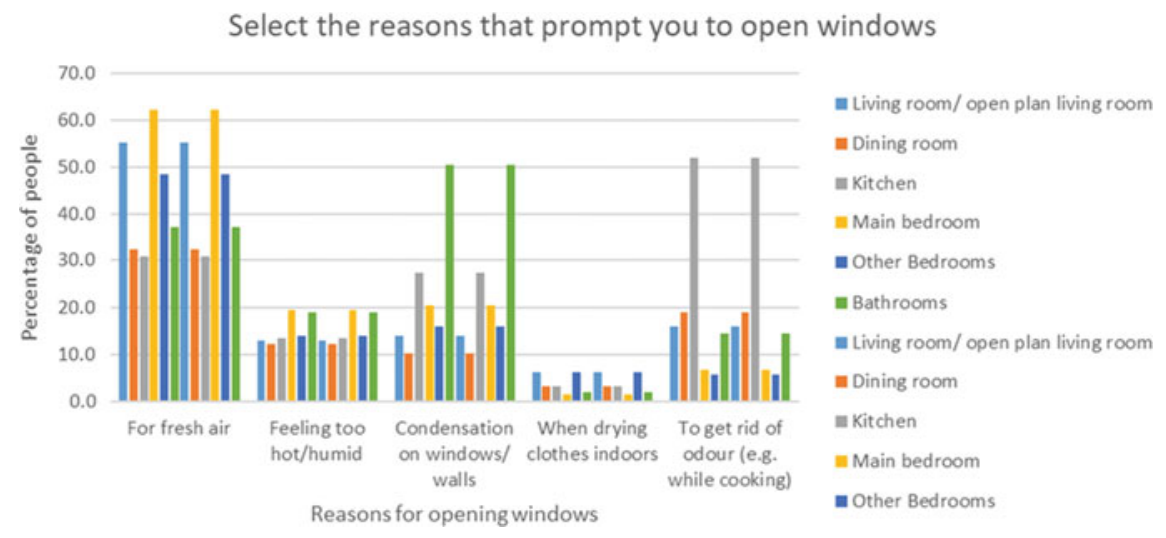

Fig. 29.4 Reasons for opening windows

windows is for fresh air (see Fig. 29.4). Other important reasons are condensation on walls and to remove odour while cooking. But energy efficiency in buildings have several dimensions. Children spend more and more time in their rooms, especially during the current pandemic situation of Covid19. The air quality therefore plays an important role in the quality of life and must be taken seriously [2]. The RSPCH and Royal College of Physicians conducted a study and provided a report based on the systemic review of the science of indoor air pollution. It has been found that the current energy efficiency of housing measures are reducing ventilation and thereby reducing the quality of air, putting the health of the residents, especially children at stake, particularly those with conditions such as asthma. Although residential building design and construction has evolved to emphasise energy efficiency and insulation, it can be argued that ventilation has been overlooked [11].

There is not enough consistent data on indoor air across the national housing stock [2]. Indoor air quality and energy efficiency are inter-related and there is a need to be addressed concurrently, for it to have any useful impact. Also, energy efficiency is one of the key aspects related to fuel poverty, as a household's fuel costs can be reduced based on increasing its energy efficiency [12].

\subsection{Conclusion}

Energy efficiency of buildings is influenced by several factors such as quality of the building envelope, wall insulation and occupant's behaviour. Occupants' behaviour is an overlooked aspect in many cases. The conducted survey shows that: 
- Occupants' behaviour could have considerable effect on energy savings in a house, due to opening of windows which will cause air infiltration and reduce the effect of envelope's insulation.

- Further studies are still needed to analyse how the issue of windows opening can be addressed and the effect of that on energy consumption and health in terms of indoor air quality.

One way to address thermal insulation, while maintaining fresh indoor air quality, is by considering heat-recovery ventilation systems as a key aspect when planning new buildings or retrofitting of old ones. Also, more research is needed in relation to air quality and its link to indoor and outdoor interface and the influence on health.

\section{References}

1. Climate change: UK government to commit to 2050 target—BBC News (2019). https://www. bbc.co.uk/news/science-environment-48596775. Accessed 18 Oct 2019

2. S. Holgate et al., The inside story: health effects of indoor air quality on children and young people, pp. 1-96 (2020)

3. B.F. Balvedi, E. Ghisi, R. Lamberts, A review of occupant behaviour in residential buildings. Energy Build. 174, 495-505 (2018)

4. International Energy Agency, Total Energy Use in Buildings: Analysis and Evaluation Methods (Annex 53) (2016)

5. Innovate UK, Building Performance Evaluation Programme: Findings from domestic projects, Swindon (2016)

6. Department of Energy and Climate Change, The Carbon Plan: Delivering our low carbon future (2011)

7. S. Salim, A. Al-Habaibeh, The Effect of Insulation on energy savings in residential buildingsmyth or reality?, in The International Conference on Energy and Sustainable Futures (ICESF) (2019)

8. K. Schakib-Ekbatan, F.Z. Çakıcı, M. Schweiker, A. Wagner, Does the occupant behavior match the energy concept of the building?-analysis of a German naturally ventilated office building. Build. Environ. 84, 142-150 (2015)

9. G.T. Wilson, T. Bhamra, D. Lilley, Reducing domestic energy consumption: a user-centred design approach, in Knowledge Collaboration \& Learning for Sustainable Innovation ERSCPEMSU Conference, Delft, The Netherlands, 25th-29th October 2010, 2010, pp. 200-222

10. D. Shipworth, Carbon, Control and Comfort I UCL Energy Institute-UCL—London's Global University (2012)

11. R. Morrison, Energy-efficient housing is reducing ventilation and trapping air pollution indoors, Mailonline

12. E. and I. S. Department of Business, Annual Fuel Poverty Statistics in England, 2020(2018 Data) (2019) 
Open Access This chapter is licensed under the terms of the Creative Commons Attribution 4.0 International License (http://creativecommons.org/licenses/by/4.0/), which permits use, sharing, adaptation, distribution and reproduction in any medium or format, as long as you give appropriate credit to the original author(s) and the source, provide a link to the Creative Commons license and indicate if changes were made.

The images or other third party material in this chapter are included in the chapter's Creative Commons license, unless indicated otherwise in a credit line to the material. If material is not included in the chapter's Creative Commons license and your intended use is not permitted by statutory regulation or exceeds the permitted use, you will need to obtain permission directly from the copyright holder.

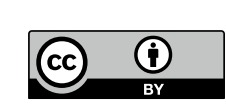

